Article

\title{
Investigation of Centrifugal Fractionation with Time-Dependent Process Parameters as a New Approach Contributing to the Direct Recycling of Lithium-Ion Battery Components
}

\author{
Tabea Sinn ${ }^{1, *(\mathbb{D})}$, Andreas Flegler ${ }^{2}$, Andreas Wolf ${ }^{2} \mathbb{D}$, Thomas Stübinger ${ }^{3}\left(\mathbb{D}\right.$, Wolfgang Witt $^{3}$, \\ Hermann Nirschl ${ }^{1}$ and Marco Gleiß ${ }^{1}$ \\ 1 Karlsruhe Institute of Technology (KIT), Institute for Mechanical Process Engineering and Mechanics, \\ Straße am Forum 8, 76131 Karlsruhe, Germany; hermann.nirschl@kit.edu (H.N.); \\ marco.gleiss@kit.edu (M.G.) \\ 2 Fraunhofer Institute for Silicate Research (ISC), Neunerplatz 2, 97082 Würzburg, Germany; \\ andreas.flegler@isc.fraunhofer.de (A.F.); andreas.wolf2@isc.fraunhofer.de (A.W.) \\ 3 Sympatec GmbH, Am Pulverhaus 1, 38678 Clausthal-Zellerfeld, Germany; \\ TStuebinger@sympatec.com (T.S.); WWitt@sympatec.com (W.W.) \\ * Correspondence: tabea.sinn@kit.edu; Tel.: +49-721-608-42410
}

Received: 11 November 2020; Accepted: 27 November 2020; Published: 1 December 2020

check for updates

\begin{abstract}
Recycling of lithium-ion batteries will become imperative in the future, but comprehensive and sustainable processes for this are still rather lacking. Direct recycling comprising separation of the black mass components as a key step is regarded as the most seminal approach. This paper contributes a novel approach for such separation, that is fractionation in a tubular centrifuge. An aqueous dispersion of cathode materials (lithium iron phosphate, also referred to as LFP, and carbon black) serves as exemplary feed to be fractionated, desirably resulting in a sediment of pure LFP. This paper provides a detailed study of the commonly time-dependent output of the tubular centrifuge and introduces an approach aiming to achieve constant output. Therefore, three different settings are assessed, constantly low, constantly high and an increase in rotational speed over time. Constant settings result in the predictable unsatisfactory time-variant output, whereas rotational speed increase proves to be able to maintain constant centrate properties. With further process development, the concept of fractionation in tubular centrifuges may mature into a promising separation technique for black mass in a direct recycling process chain.
\end{abstract}

Keywords: fractionation; tubular centrifuge; rotational speed control; particle size analysis; lithium iron phosphate; LFP; carbon black; lithium-ion battery; direct battery recycling; recovery

\section{Introduction}

The threat of global climate change and environmental pollution are, among other reasons, fueling the electric revolution in mobility [1], which in turn increases the demand for powerful batteries. Lithium-ion batteries (LIBs) are mostly regarded as most suitable battery type for this and other applications [2]. However, the performance of every LIB suffers from ageing mechanisms which inevitably lead to its withdrawal, eventually [3]. With a foreseeable increasing number of LIBs in use and withdrawn thereafter, the amount of LIB material that can and should be recycled increases equally, since permanent disposal seems not to become a practical option for the upcoming mass of LIBs. Environmental issues again and scarce resources primarily drive the development of comprehensive, flexible and large-scale suitable recycling strategies for the valuable LIB materials [4]. 
At present, there are three kinds of approaches for the recycling of LIBs, that are pyrometallurgy, hydrometallurgy and direct recycling $[2,3,5]$.

Pyrometallurgical metal recovery means the thermal decomposition of LIBs in high-temperature furnaces. This comparatively simple procedure is versatile concerning the actual feed-in composition, but the resulting gases are partly detrimental and require post-processing [6] while the obtained slag and metal alloy contain comparably few kinds of metals and in low quality $[4,7]$.

Hydrometallurgical reclamation methods comprise the leaching of metals from active material in aqueous solutions of acids and reducing agents. Numerous steps of subsequent precipitation reactions allow one to recover a wider variety of higher quality metals compared to pyrometallurgy $[8,9]$. However, it is more complex and premature sorting and separation of the LIB constituents is advisable in order to significantly improve the efficiency of the hydrometallurgical process chain [2].

The two approaches named have in common to basically recover metallic LIB components, but not to preserve the original active materials and their morphology. By contrast, in direct recycling, electrode material is removed from the electrodes and reconditioned with the objective to regain active materials that can directly be reused in the manufacture of fully functional "recycling-LIBs". Among the three approaches named, it enables recovery of the highest absolute amount and diversity of LIB-constituents [3]. Pre-sorting as specifically as possible is expedient in this approach, too, but dispensing with numerous intermediate steps and expensive processing afterwards by mainly concentrating on physical separation techniques, it could also render recycling more lucrative. Manifold physical separation techniques exist that might be worth considering. They share the characteristics to exploit different physical properties of the active materials (like density, particle size, ferromagnetism or hydrophobicity). Admittedly, a complete direct recycling process chain for LIBs is complex to establish.

One central element of a direct recycling process chain after shredding and pre-sorting is the separation of the black mass components. The black mass is most commonly an aqueous dispersion of the electrode coatings comprising metal oxides, conductive carbon black $(\mathrm{CB})$ and binders. There are concepts for this crucial step relying on physical separation. For example, one approach to separate CB from metal oxides in the black mass is froth flotation [10], making use of the hydrophobicity of carbon. In most cases, binders must be eliminated firstly in order to release the active material for further treatment [11]. Research is taking direction towards the development of water-soluble binders, which facilitates treatment steps in recycling chains besides possible improvements in other properties like mechanical flexibility [12].

This paper concentrates on the separation of exemplary cathode materials for a start, that are lithium iron phosphate $\left(\mathrm{LiFePO}_{4}, \mathrm{LFP}\right)$ and CB besides the binders carboxymethylcellulose (CMC) and styrene butadiene rubber (SBR), dispersed in water. A novel separation strategy for these materials is presented, centrifugation of the dispersion with the intention to fractionate LFP and CB.

Centrifugation is a familiar unit operation in process engineering $[13,14]$, but its full potential in relation to LIB recycling has not been harnessed yet. Naturally, the fundamental separation mechanism in centrifuges is the differing settling/sedimentation behavior of constituents according to the specific acting centrifugal force. Usually, like in this work, dense solid particles sediment in a liquid. The force depends on numerous properties of the particles, mainly density and size [15]. Differences in these properties could be exploited to fractionate particles of different kinds utilizing a centrifuge, as treated in the present report for LFP and CB particles. Since the resulting centrifugal forces are relatively weak for both particle species given, a strong centrifuge type has been chosen, precisely a tubular centrifuge [16-18]. Although tubular centrifuges offer the advantage of high centrifugal forces thanks to their quite simple design without a means to transport sediment out, the same also results in only semi-continuous operation and transient behavior [19,20]. With unaltered operational settings, namely feed flow rate and rotational speed, the separation becomes less efficient over time. If constant output quality is desired, this complicates process design significantly. 
Earlier works like $[21,22]$ have shown for different particulate systems that various operational settings influence the output of the tubular centrifuge and notable differences in the separation behavior can be observed. Building upon these earlier examinations, this paper's subject is the influence of different operational settings on the separation and fractionation quality for a mixed dispersion containing the cathode materials LFP and CB. Thereby the focus lies firstly on the temporal development of the separation process applying different settings. Secondly, the authors investigate a novel approach to achieve semi-continuous fractionation with constant output by adapting the rotational speed over time. A detailed comparison is made between the common approach to set constant operational parameters on the one hand, based on two exemplary cases with constantly weak and constantly strong separation conditions (low and high rotational speed), and on the other a new strategy to achieve constant output with desired properties as a third case, comprising a sequence of increasing rotational speed. This is a novelty in centrifuge operation and has not been applied for tubular centrifuges yet, neither has it been taken into consideration as a possible way to assess high-speed centrifugation to recover LIB materials. Since the focus of this paper lies on rotational speed variation, feed flow rate was kept constant for the time being.

\section{Materials and Methods}

\subsection{Tubular Centrifuges and Fractionation by Sedimentation Behavior}

As a representative of solid-bowl centrifuges, tubular centrifuges mainly consist of a narrow cylindrical rotor with bearings at its foot and top ends, a construction which allows high-speed rotation offering high centrifugal forces up to $100,000 \times g$ in some cases [22]. Naturally, the fundamental separation mechanism in tubular centrifuges is settling/sedimentation of denser constituents than the carrier medium due to the acting centrifugal force.

In this work, dense solid particles that are LIB cathode materials sediment in water. Dispersion is injected into the rotor via a nozzle at one end (in this work, at the bottom) as feed, flowing upward along the rotation axis. Particles that sediment on their way towards the outlet accumulate at the inner wall of the rotor, forming a liquid-saturated sediment. Residual dispersion, i.e., liquid and particles that have not reached the sediment during their residence time, leaves the rotor at the upper side as centrate. There is no device to transport the sediment out of the rotor, it accumulates up to a maximum extent where no particles can be separated anymore. This is the latest point to stop and open the rotor for manual sediment extraction. The centrifuge used in this work and its geometric dimensions are schematically illustrated in Figure 1a, where the cross-sectional view also outlines the characteristic cone-shaped sediment build-up in the tubular rotor explained below. Relevant geometrical dimensions are the rotor length $L_{R}$, radial range of the inlet weir $R_{W}$, radial range of the drum (to the inner wall of the rotor) $R_{D}$ and the radial position of the sediment surface $R_{S}(l, t)$, a dimension varying with the regarded axial position $l$ and process time $t$ on account of the progressive sediment formation.

Sedimentation behavior, or more precisely, the specific sedimentation velocity of particles, determines which particles are separated in the centrifuge rotor during their residence time. For appropriate process design, a realistic description of the sedimentation velocities is therefore helpful (besides a description of sediment build-up, which is not further treated in this paper, refer for example to [23-28] for more details). Basically, the particles' settling velocities depend on their size and density, according to Stokes' Law [15] in a centrifugal field:

$$
\begin{gathered}
u_{S}(x)=\frac{x^{2} \cdot\left(\rho_{S}-\rho_{L}\right) \cdot r \cdot \omega^{2}}{18 \cdot \eta_{L}} \\
\text { with } \omega=2 \pi \cdot n
\end{gathered}
$$

where $u_{S}$ is Stokes' settling velocity, $x$ designates the particle diameter, $\rho_{S}$ and $\rho_{L}$ the solid (particle) and liquid mass density, $r$ the radial position of the particle and $\omega$ the angular velocity, calculating with $n$ 
denoting the rotational speed, i.e., the number of revolutions per time. Real settling velocities observed may differ from this idealized treatment due to effects of particle-particle interactions that can arise as a result of manifold reasons, like particle surface properties [29], shape and concentration-dependent effective viscosity [30,31] that lead to acceleration or hindrance (hindered settling) of the particles [24]. Generally, those real settling velocities are measurable and subject to research up until now $[30,32,33]$. Concluding a functional correlation of experimental findings allows to simply calculate the real settling velocity $u_{\text {real }}(x, c)$ approximately by applying the following expression:

$$
u_{\text {real }}(x, c)=u_{s}(x) \cdot h(x, c)
$$

with $h(x, c)$ being the hindered settling function determined from experimental data, depending on particle size and particle concentration $c[25,31]$. Such measurements can for example be performed in a LUMiSizer laboratory centrifuge (L.U.M. GmbH, Berlin, Germany) [23,34].

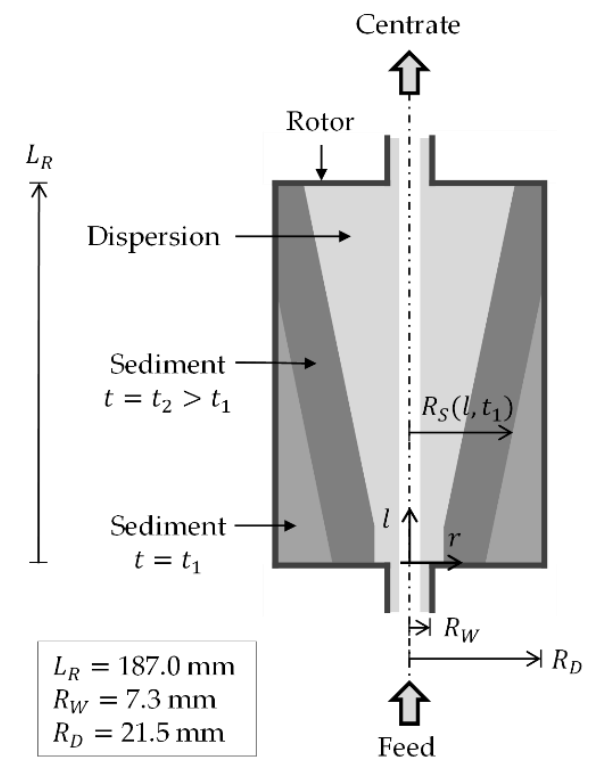

(a)

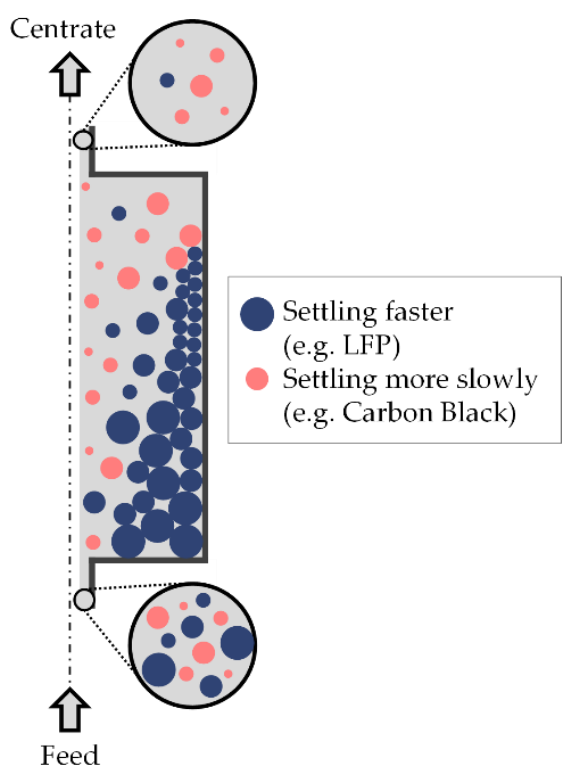

(b)

Figure 1. Schematic illustration of the tubular centrifuge and particle sedimentation, in cross-sectional view. (a) Tubular centrifuge with geometrical dimensions and progressive sediment build-up. Geometry data given for CEPA Z11; (b) Particles in the centrifuge (particle sizes exaggerated): Feed dispersion containing two particle systems, specific settling behavior and sediment build-up for almost complete fractionation, centrate containing nearly solely the particle system settling more slowly (Blue: Faster-settling component, representing LFP; Red: Component settling more slowly, representing carbon black).

A particle collective consequently shows a settling velocity distribution, according to its composition. Faster settling particles are more likely to be separated. Pursuant to their properties (cf. Section 2.2), LFP is the faster settling material compared to CB, in this work. The discrepancy in their settling behaviors indicates that LFP and CB can theoretically be completely fractionated, i.e., separated by species, applying a sedimentation-based separation apparatus like a tubular centrifuge.

The overarching objective of such a process, like in this paper, is to recover the components formerly mixed in the feed dispersion as purely as possible despite possible practical challenges. Hence, an appropriate measure to examine the success of a fractionation process is the separation efficiency. It is defined as the ratio of to the mass of material $i$ that has been separated in the apparatus $\left(m_{\text {sed }, i}\right)$ over the mass of $i$ that has entered the centrifuge $\left(m_{i n, i}\right)$ (Equation (4), first part) and can also be calculated inversely applying the mass of $i$ leaving the centrifuge in centrate $\left(m_{\text {centrate }, i}\right)$ (Equation (4), 
second part). Assuming the volumetric flow rate of liquid to be approximately constant, calculation via the concentrations in feed, sediment or centrate $\left(c_{f e e d, i}, c_{\text {sed }, i}, c_{c e n t r a t e, i}\right)$ is also possible (Equation (5)):

$$
\begin{gathered}
T_{i}=\frac{m_{\text {sed }, i}}{m_{\text {in }, i}}=1-\frac{m_{\text {centrate }, i}}{m_{\text {in }, i}} \\
T_{i}=\frac{c_{\text {sed }, i}}{c_{\text {feed }, i}}=1-\frac{c_{\text {centrate }, i}}{c_{\text {feed }, i}}
\end{gathered}
$$

In the regarded process, $i$ can stand for the solid material overall as well as the solid components of interest, namely LFP or CB. Accordingly, the envisaged complete fractionation can be expressed in terms of the separation efficiencies of the two particulate systems to be fractionated with values $T_{L F P}=1$ (or $100 \%$ ) and $T_{C B}=0$ (or $0 \%$ ), implying that the entire amount of LFP entering the centrifuge is separated while CB is not separated at all, i.e., not found in the sediment. The means to achieve this is an appropriate setting of the process operational parameters, namely rotational speed of the centrifuge $n$ and volumetric flow rate of the feed dispersion $\dot{V}$. In practice, this ideal case of complete fractionation is not entirely feasible since a certain mixing due to small vortexes or secondary flows in the rotor $[17,21,35]$ cannot be excluded, which can lead to slight impurities in sediment and centrate, however. As explained in more detail below, tubular centrifuges are commonly characterized by a time-dependent separation behavior. Thus, a sensitive examination must also include the development of the separation efficiencies over process time, $T_{L F P}(t)$ and $T_{C B}(t)$. The optimal setting adapts to the time-variant apparatus behavior, leading - in case of complete fractionation again-to consistent process outputs $T_{L F P}(t)=100 \%=$ const. and $T_{C B}(t)=0 \%=$ const. over the entire process time, despite the transient separation conditions.

The reason for the time-dependency of a tubular centrifuge's separation behavior lies in the progressive sediment formation $[17,20,35]$. As explained above, particle collectives settle with their specific distribution of settling velocities. Generally, when injected into a tubular centrifuge, particles settling faster will be separated closer to the inlet than slower ones. With sediment gradually occupying free space and the feed flow rate set constant, the axial flow velocity of the dispersion in the rotor accelerates, shifting the balance of forces acting on the particles. As a result, the individual separation position of a particle shifts axially towards the outlet with increasing filling level, which is also why the filling of the rotor typically proceeds from the inlet towards the outlet side, leaving a truncated cone-shaped free space for the dispersion to flow through, as outlined in Figure 1. Figure $1 \mathrm{~b}$ illustrates in more detail the axial distribution of particles with different settling velocities in sediment and dispersion for the case of a nearly complete fractionation, where only a few particles of the slower settling species are found in the sediment close to the outlet.

The shifting balance of forces for the individual particles is equivalent to time- and position-dependently weakening separation conditions and decreasing separation efficiency. Increasingly faster (i.e., usually bigger sized) particles cannot be separated anymore. [23,36] describe the separation efficiency depending of the operational parameters, that are rotational speed $n$ and feed flow rate $Q$. A temporal decrease in separation efficiency can theoretically be counteracted by an appropriate raise in rotational speed [17] and/or reduction of feed flow rate.

Working further on this foundation, the effect of different operational settings on the separation efficiencies of LFP and CB particles, entering the centrifuge in a mixed dispersion, are examined in this paper. Besides detailed investigations with LFP and CB about the influence of the operational parameters $n$ and $Q$, a more time-resolved study is still lacking and shall also be contributed with this work. Its purpose is to evaluate three different operational strategies. While the dependency of the feed flow rate is not yet regarded in this paper and its value remains unaltered throughout the cases, three settings for rotational speed are compared in detail. In the first case, rotational speed is set to a constant low value $(20,000 \mathrm{rpm})$ with the intention to obtain no CB in the sediment at all. However, this might be accompanied by a high loss of LFP, which shall be minimized in the second case that 
is run at a constantly high rotational speed $(40,000 \mathrm{rpm})$. This way, though, settling of CB into the sediment has to be considered. Both constant rotational speed settings do not take the temporal change in separation behavior into account. To do so, in the third case, a temporal increase of rotational speed is applied in order to cover the estimated optimal setting over the entire process time, which in a different set-up [17] indicated to be a convenient method. This rotational speed trajectory has been defined beforehand utilizing a simplified flowsheet simulation of the process, which is basically developed at the basis of $[23,36]$. However, the simulation is still subject to further research and will be elucidated and published separately in the future.

\subsection{LIB Cathode Particle Systems and Binders Used}

The feed dispersion used for all experiments is a mixed dispersion of LFP, Super C65/carbon black (CB) particles as well as binders, namely carboxymethylcellulose (CMC) and styrene-butadiene rubber (SBR), diluted with demineralized water to an overall solids content of $1.6 \mathrm{wt} \%$. Table 1 below lists the composition of the solids mixture, relevant properties of all constituents and their envisaged behavior during centrifugal fractionation.

Table 1. Components in the feed dispersion and their individual properties.

\begin{tabular}{ccccc}
\hline $\begin{array}{c}\text { Solid Constituent } \\
\text { (Acronym) }\end{array}$ & Solids Fraction & $\begin{array}{c}\text { Carbon } \\
\text { Content }\end{array}$ & Density & $\begin{array}{c}\text { Behavior during Complete } \\
\text { Fractionation }\end{array}$ \\
\hline $\begin{array}{c}\text { Lithium Iron } \\
\text { Phosphate (LFP) }\end{array}$ & $85 \mathrm{wt} \%$ & $\begin{array}{c}13 \mathrm{wt} \% \\
(\text { Coating) }\end{array}$ & $3.5 \mathrm{~g} / \mathrm{cm}^{3}$ & $\begin{array}{l}\text { Fast-settling component. } \\
\text { Settles completely and purely }\end{array}$ \\
\hline $\begin{array}{c}\text { Super C65/Carbon } \\
\text { Black (CB) }\end{array}$ & $10 \mathrm{wt} \%$ & $67 \mathrm{wt} \%$ & $1.9 \mathrm{~g} / \mathrm{cm}^{3}$ & $\begin{array}{l}\text { Slowly settling component. } \\
\text { Stays in centrate }\end{array}$ \\
\hline $\begin{array}{c}\text { Carboxymethyl-cellulose } \\
\text { (CMC) }\end{array}$ & $2.5 \mathrm{wt} \%$ & $20 \mathrm{wt} \%$ & $1.1 \mathrm{~g} / \mathrm{cm}^{3}$ & $\begin{array}{l}\text { Not affected by centrifugal } \\
\text { force, but partly settling } \\
\text { attached to particles }\end{array}$ \\
\hline $\begin{array}{c}\text { Styrene Butadiene } \\
\text { Rubber (SBR) }\end{array}$ & $2.5 \mathrm{wt} \%$ & $1.0 \mathrm{~g} / \mathrm{cm}^{3}$ & \\
\hline
\end{tabular}

Figure 2a depicts the particle size distributions (PSDs) of LFP and CB particles. The PSDs have been measured by means of laser diffraction (cf. Section 2.4). With regard to the PSDs of the individual particle systems, LFP is partly coarser than CB on the whole, but a large overlap from $0.2 \mu \mathrm{m}$ up to about $10 \mu \mathrm{m}$ is evident. Though, according to the density data in Table 1 and remarks in Section 2.1, LFP can clearly be referred to as the faster settling species. Consulting the scanning electron microscope (SEM) images in Figure $2 \mathrm{~b}$ in addition, LFP primary particles are rather ellipsoid and roughly $500 \mathrm{~nm}$ in diameter, while CB primary particles are much smaller with less than $100 \mathrm{~nm}$ in diameter and form branched agglomerates.

The binders are assumed to behave virtually inert to the centrifugal field due to their density. Reasons also include CMC being soluble in water is not to be regarded as rigid "particles" and SBR present as only nano-sized polymer fibers. However, it cannot be excluded that they attach to LFP and $\mathrm{CB}$, complicating a general assumption regarding their principal location during centrifugation and therefore the assessment of the detailed composition of samples (cf. Section 2.4).

To evaluate the separation efficiency of LFP and CB in detail, the total carbon content of samples was determined with a LECO C744 (cf. Section 2.4) system. The dispersion component containing the most carbon is $C B$, naturally. However, the results must be interpreted with caution since the other components comprise carbon as well. $2.2 \mathrm{wt} \%$ of the LFP particles is, more precisely, a carbon coating which makes up $13 \mathrm{wt} \%$ of the total carbon mass and the binders for their part contribute $20 \%$ to total carbon in the feed dispersion. So by and large CB makes up about two thirds of the carbon measurable in a feed sample and even complete fractionation will not deliver carbon-free samples. 


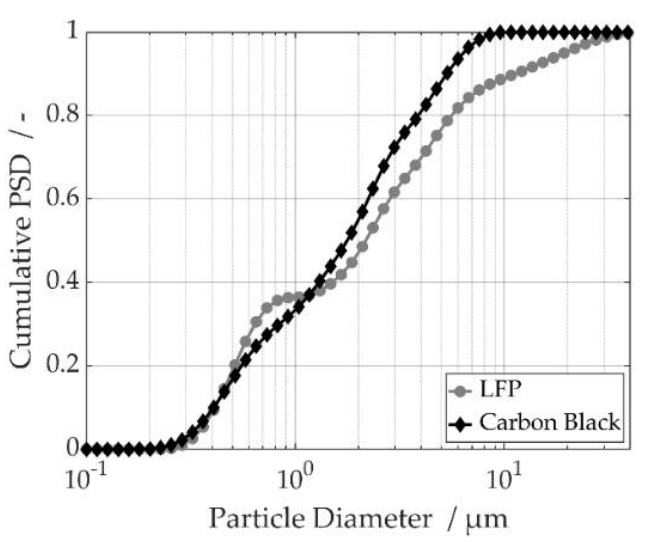

(a)

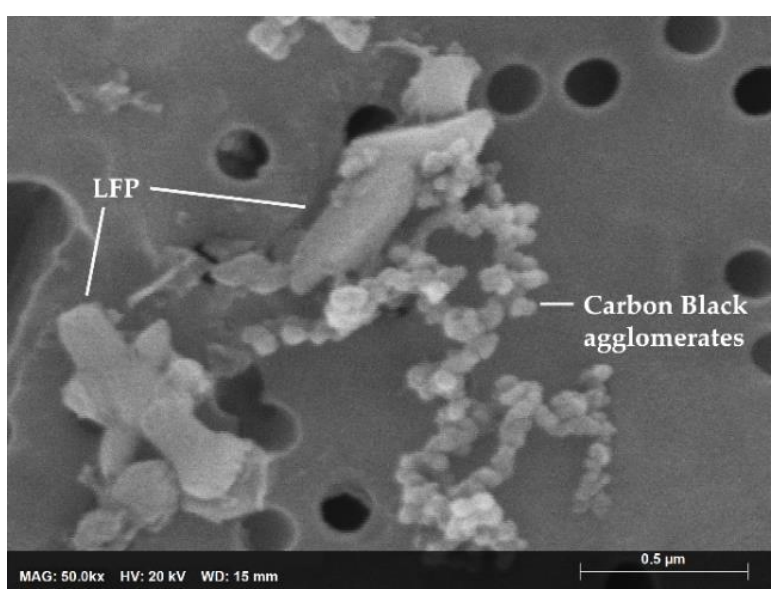

(b)

Figure 2. Particles in the feed dispersion. (a) Particle Size Distributions of LFP (grey) and Carbon Black (black) particles. (b) SEM image of LFP and Carbon Black particles on a nucleopore filter.

Figure $2 \mathrm{~b}$ is an image of particles on a filter without liquid, but it can be seen as an indication for the formation of CB agglomerates and LFP-CB mixed-species agglomerates. Agglomerates possibly form and break at different stages of the procedure including feed preparation and centrifugation, which cannot certainly be said or quantified at present. For all repeating experiments concerning one case treated in this work, an individual batch of cathode material paste was diluted to be used as feed dispersion. PSD measurements for the three feed dispersions have been carried out as well (cf. Section 2.4) and a strong tendency to agglomerate was visible during successive measurements within feed samples of case 2 and 3.

An overview of the characteristic particle sizes $x_{10}, x_{50}$ and $x_{90}$, including mean values and standard deviations, as well as measured PSDs in detail (averaged) is displayed in Figure 3.

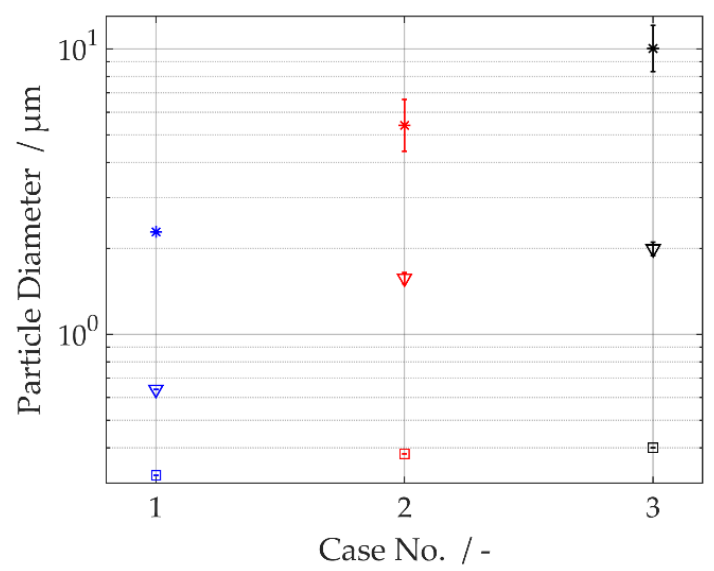

(a)

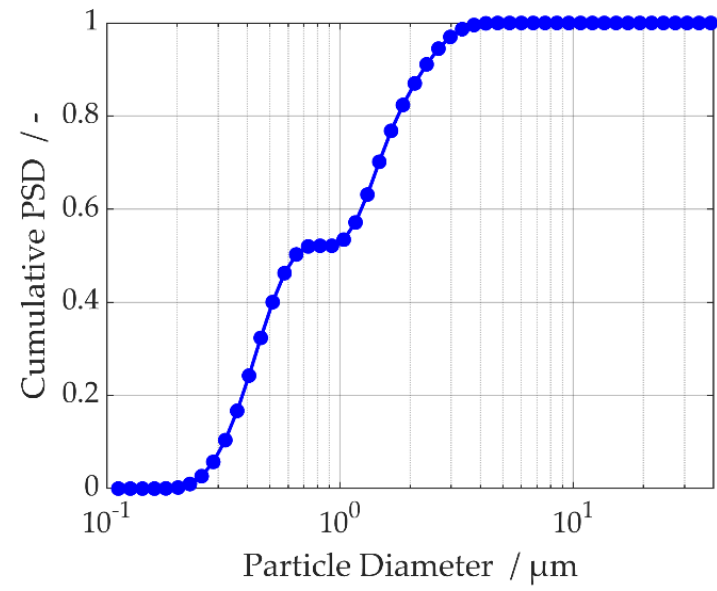

(b)

Figure 3. Cont. 


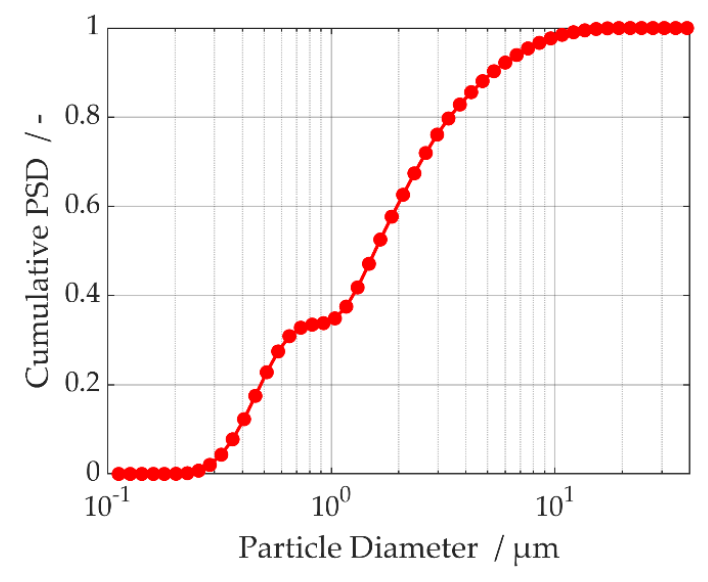

(c)

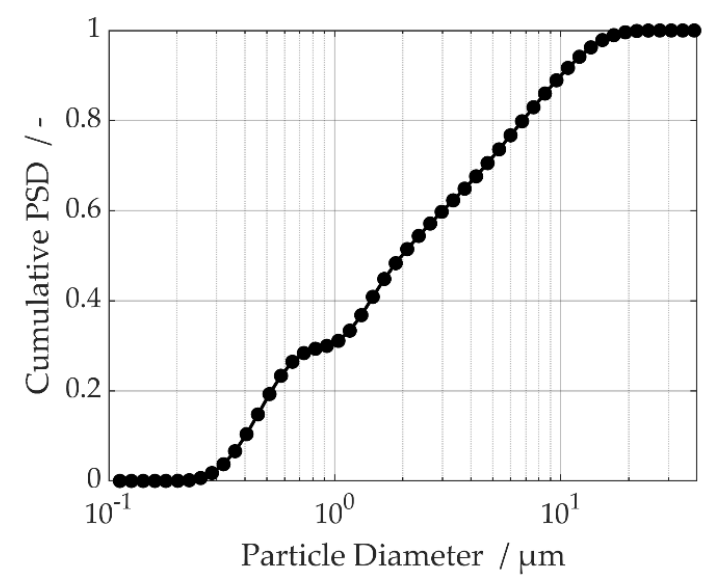

(d)

Figure 3. Feed particle size distributions used in the three cases. Blue: 20,000 rpm (Case 1); Red: 40,000 rpm (Case 2); Black: Increasing rotational speed (Case 3). (a) Characteristic particle sizes, squares: $x_{10}$; triangles: $x_{50}$ with dashed lines as guides to the eye; stars: $x_{90}$. (b-d) Detailed particle size distributions for the three cases, averaged.

The high standard deviations, especially for the $x_{90}$ values, reveal progressing agglomeration among the coarser particles. Therefore, it must be kept in mind that potential for agglomerate formation and breakage exists in this work, too, and probably differs between the three cases regarded. Mainly case 2 and 3 findings might be affected.

\subsection{Experimental Set-up and Procedure}

The entire experimental set-up, important parameters and sampling locations are outlined in Figure 4. Feed dispersion is stored in a continuously stirred tank and pumped into the centrifuge rotor using a membrane pump equipped with a pulsation damping pressure retention valve. For all experiments shown in this paper, the flow rate has been set to $\dot{V}=200 \mathrm{~mL} / \mathrm{min}$. Injection into the rotor is achieved via a nozzle attached to the rotor's bottom end. The tubular centrifuge used in this work is the model Z11 by CEPA (Carl Padberg Zentrifugenbau GmbH, Lahr im Schwarzwald, Germany), which can run on rotational speeds between $20,000 \mathrm{rpm}$ and $54,000 \mathrm{rpm}$ (equals $10,000 \times g$ to $70,000 \times g$ at the inner wall surface). It is equipped with a touch panel allowing to define rotational speed manually, which is utilized to enter both the constant values in the first two cases and the temporal sequence in the third case. It should be noted for the third case that the manual input of values necessitated a curtailing of the calculated rotational speed values to a feasible timetable. So, although the calculation was made for one value per second, the input was limited to one value every $30 \mathrm{~s}$ and the actual input was merely a step function. The rotational speed settings are displayed in Figure 5. After passing the rotor with a nominal volume of $250 \mathrm{~mL}$, centrate is discharged via the run-off tray and hose connection into a collecting tank. Samples for subsequent centrate analyses were taken every three minutes at the hose connection, too. To begin an experiment, the rotor was set on the (initial) rotational speed and demineralized water was fed into the rotor. When the rotor was completely filled and water ran out, feed was switched to the dispersion tank. Experimental time started counting when dispersion entered the nozzle. Duration of every experiment in this paper was $30 \mathrm{~min}$, three repeating experiments have been carried out per case. After disassembly, sediment samples were taken at the bottom (B), middle (M) and top (T) positions and resuspended in demineralized water. Feed samples (Figure 3) were taken once per case and directly out of the stirred feed tank before the experimental procedure began. 


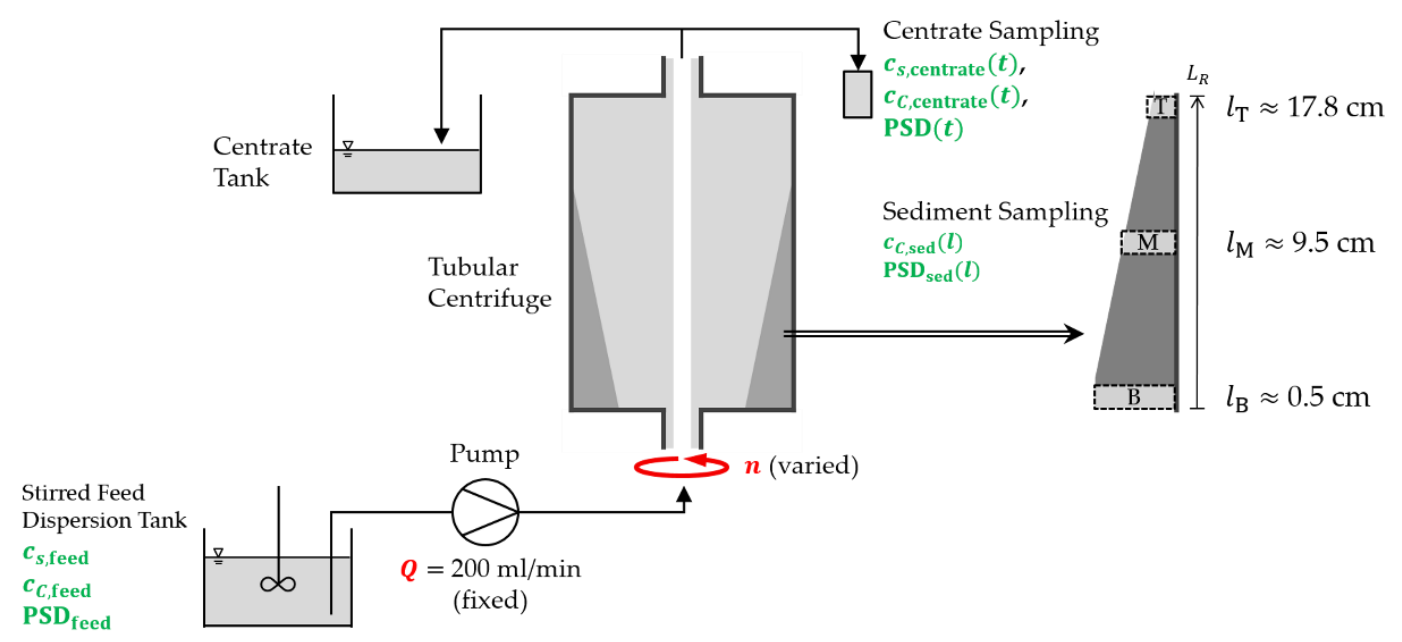

Figure 4. Outline of the experimental set-up with components (black/grey), operational parameters (red) and sampling locations with properties analyzed (green).

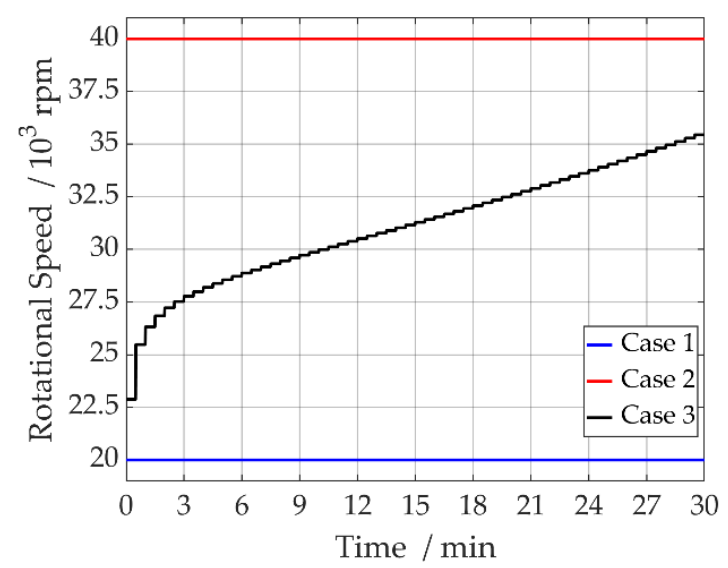

Figure 5. Rotational speed settings for the three cases examined: Blue: Case 1, constantly low; Red: Case 2, constantly high; Black: Case 3, stepwise increase.

\subsection{Analytical Methods}

All centrate samples have been analyzed concerning the overall solids content by means of drying and applying Equation (5) to calculate overall separation efficiency. According to capacities given, centrate and sediment samples have also been examined with regard to the particle size distribution (PSD) and carbon content. For this purpose, samples of two sampling times had to be mixed in each case, i.e., the first and second were mixed, the third and fourth, and so on. Thus, the PSD and carbon content measurements represent quasi-averaged states. For carbon content measurements, the mixed samples were dried and the solid remains grinded using a mortar.

Measurements of particle size distribution have been carried out with an advanced laser diffraction sensor based on HELOS technology (Sympatec GmbH, Clausthal-Zellerfeld, Germany). Equipped with a blue laser source and multi-element photo detectors for forward, backward and wide-angle light scattering detection, the device was utilized for at least six repeated measurements per sample. Measurements were performed in a flow-through cuvette with sample supply achieved with the wet dosing station LIQXI (also by Sympatec).

Carbon content measurements for the dry, grinded samples took place in a LECO C744 (LECO Instrumente $\mathrm{GmbH}$, Mönchengladbach, Germany), including a high frequency induction furnace and non-dispersive infrared (NDIR) detection cell. Two to three repeating measurements have been executed according to the obtainable mass per sample. 


\section{Results}

For a sound evaluation of the experimental data, all the results must be sensibly combined. To enhance clarity, the section is divided in two subsections. The first one treats the results concerning the centrate, where particular attention is paid to the time-dependent development. In the second section the results concerning the sediment measurements are presented, which are naturally linked to the centrate analysis.

\subsection{Time-Dependent Centrate Analysis}

Figure 6 displays the calculated separation efficiency referring to the overall solids content over the examined experimental duration for the three cases. The weak separation conditions $(20,000 \mathrm{rpm})$ clearly led to the least solids yield as sediment, showing the lowest start value of $89 \%$ and dropping rapidly down to $72 \%$. The strongest separation conditions $(40,000 \mathrm{rpm})$ and the rotational speed increase yield roughly identical outputs, especially including the bars (here marking minimum and maximum of the single values calculated from measurements). However, the mean values in case 2 reveal a minor tendency to decrease from the first to the latest (93 to $90 \%$ ) measurement, while case 3 lets one urmise a relatively constant separation efficiency of 91\%. All in all, the high overall solid separation efficiencies in case 2 and 3 already reveal that not only LFP, but also CB has been separated from the feed dispersion to a certain extent.

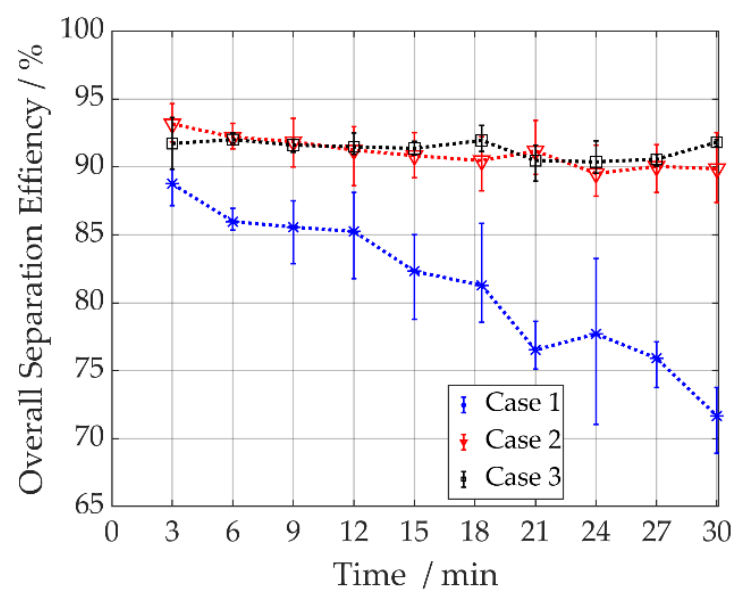

Figure 6. Overall separation efficiency for the three cases over time. Blue: 20,000 rpm; Red: 40,000 rpm; Black: Increasing rotational speed. Squares: Mean values; bars: Minimum/maximum of the three repeating experiments; dashed lines are guides to the eye.

Figure 7a sums up the PSD measurement results for the centrate samples, showing the mean results and standard deviations for $x_{10}, x_{50}$ and $x_{90}$ over time and per case. Case 1 evinces the most significant increase in all characteristic particle sizes over time, as well as remarkably higher $x_{90}$ sizes in general. Case 2 centrate contains the finest particles in all respects, but a modest increase leads to nearly identical $x_{10}$ compared to case 3 towards the end of the experimental time. The rotational speed increase in case 3 seems to yield almost constant PSD characteristics slightly larger than those in case 2. A closer look at the PSDs in detail (Figure 7b-d) evinces again the strong resemblance of centrate PSDs in case 2 and 3. In the beginning, case 2 centrate contains distinguishably finer particles, but shifts visibly approaching case 3 while the latter's PSDs remain virtually identical over the entire time. Both case 2 and 3 only comprise the fine particles from the feed PSDs (the fraction furthest to the left, cf. Figure 3) whereas case 1 centrate contains the coarser fraction of the feed to a great extent, which causes the high $x_{90}$ values in Figure 6. The share of the coarser fraction increases over time, too. So it could be assumed from the PSDs that the centrate in case 2 and 3 contains a considerable amount of $\mathrm{CB}$, namely rather the finer particles, besides probably only few and fine LFP particles 
from the feed dispersion. Case 1, on the contrary, might even still contain LFP particles and nearly all the CB. Carbon content measurements provide greater clarity. Results for the centrate samples are depicted in Figure 8. Except for the first value, case 1 centrate samples show the lowest carbon content decreasing inside the small range between about $49 \% \mathrm{C}$ to $47 \% \mathrm{C}$. This implies that not only $\mathrm{CB}$, but also a portion of LFP remains in the centrate at 20,000 rpm, even at the beginning when there is no considerable amount of sediment in the rotor. Also, the share of LFP seems to be slightly increasing over time, lowering the carbon content, but also an increasing number of $\mathrm{CB}$ particles must stay in centrate regarding the rapidly dropping overall separation efficiency (Figure 6), on the whole. Thus, it could be concluded that both species' separation efficiencies sink, but $T_{L F P}$ a little faster than $T_{C B}$ does. In contrast, case 2 shows a significant increase in carbon content over time from $47 \% \mathrm{C}$ to nearly $55 \% \mathrm{C}$. This suggests that a certain share of (fine) LFP particles is present, shrinking over time. Taking into account the overall fine, but slightly coarsening centrate PSDs and the marginally decreasing overall separation efficiency, it also means that both fine CB and fine LFP particles are contained in the centrate, but with the share of $C B$ particles growing fast, $T_{C B}$ probably declines more rapidly than $T_{L F P}$ does. Finally, case 3 centrate samples have generally the highest carbon contents measured. They increase to a small extent from about $52 \%$ C to $56 \%$, which suggests that there are still some LFP particles contained, though their fraction diminishes. Hence, the observed mostly steady centrate overall solids content and PSDs are consistently supplemented by a practically constant carbon content.

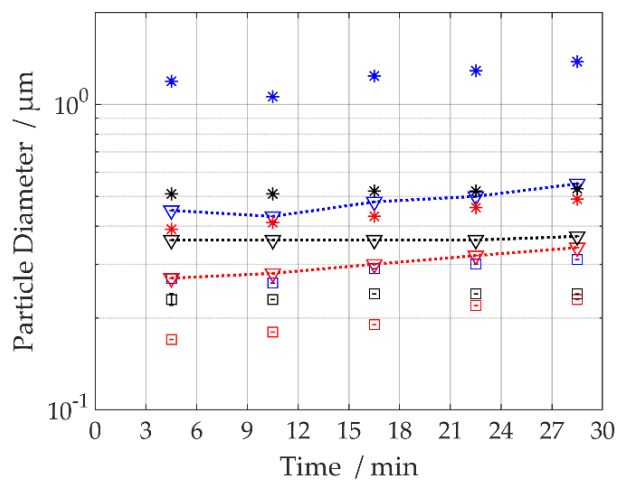

(a)

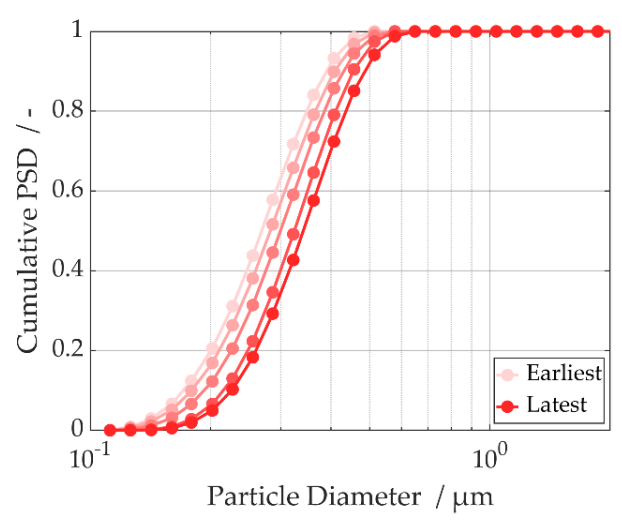

(c)

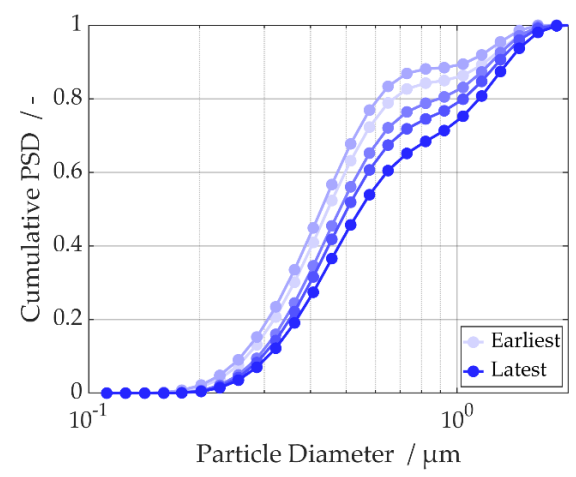

(b)

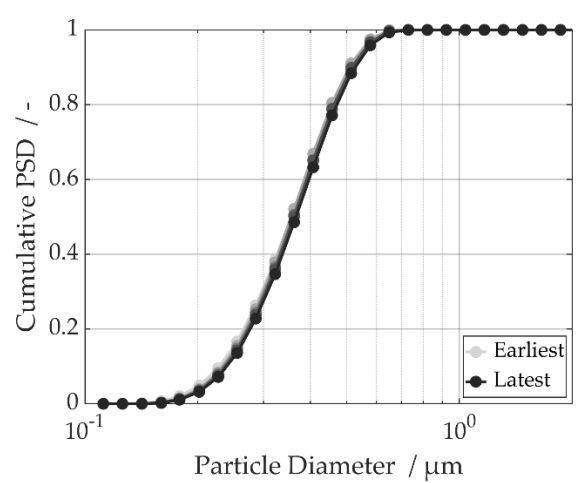

(d)

Figure 7. Centrate particle size distributions for the three cases over time. Blue: 20,000 rpm; Red: 40,000 rpm; Black: Increasing rotational speed. (a) Characteristic particle sizes, squares: $x_{10}$; triangles: $x_{50}$ with dashed lines as guides to the eye; stars: $x_{90}$. (b-d) Detailed particle size distributions for the three cases over time; light color: Earliest measurement; darkening shade with progressing time until darkest color: Latest measurement. 


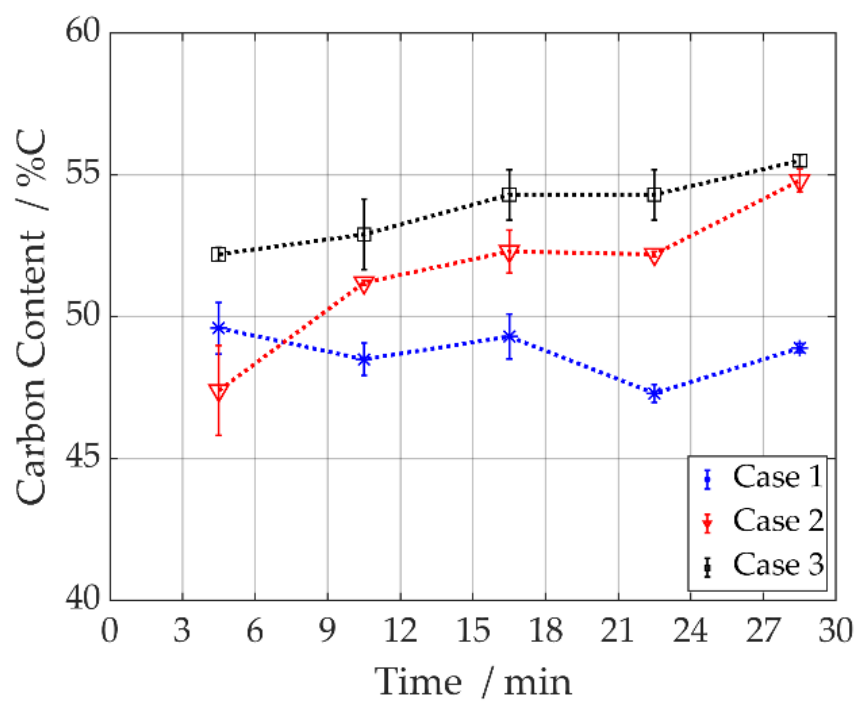

Figure 8. Centrate overall carbon content for the three cases over time. Blue: 20,000 rpm; Red: 40,000 rpm; Black: Increasing rotational speed. Squares: mean values; bars: Standard deviations; dashed lines are guides to the eye.

\subsection{Sediment Analysis}

The sediment analysis complicates compared to the centrate evaluation as they cover the entire sediment height, i.e., a cross-section of the integral process development, which impedes definite interpretations of the measurements.

The PSDs of the resuspended sediment samples are delicate to evaluate since a strong tendency to agglomerate is observed in most of the samples. Figure 9a depicts the mean results and standard deviations in $x_{10}, x_{50}$ and $x_{90}$ for the three cases at bottom, middle and top of the rotor. Case 2 and 3 show the expected trend towards finer particles in direction to the top of the rotor while case 1 exhibits rather steady characteristics over the three sampling positions. Case 3 exhibits the coarsest particles at the bottom compared to the other cases. In the middle and especially at the top, case 2 and 3 reveal quite close PSD characteristic sizes.

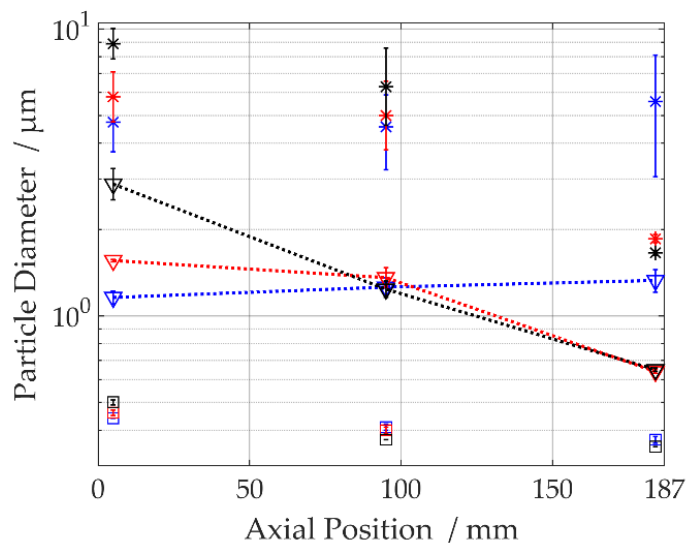

(a)

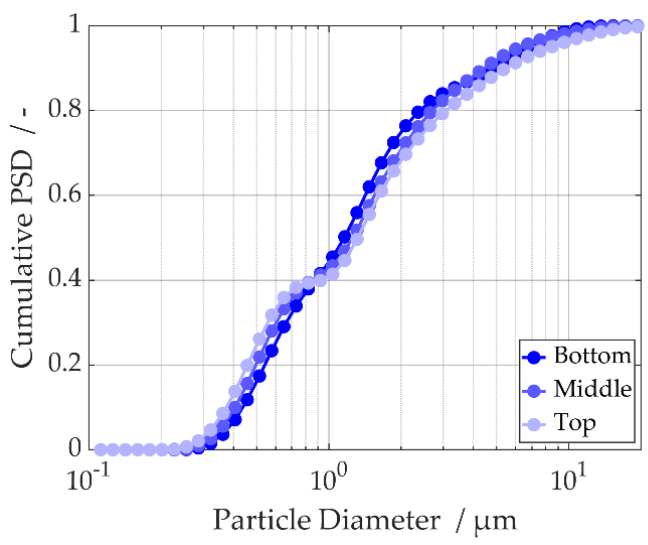

(b)

Figure 9. Cont. 


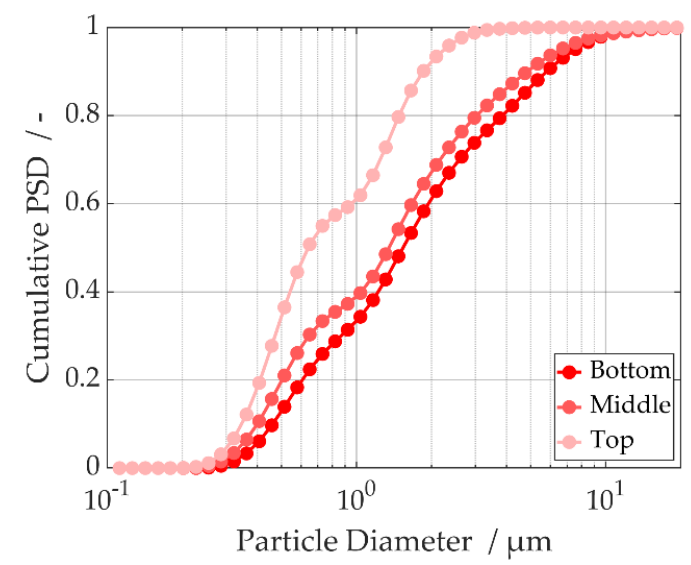

(c)

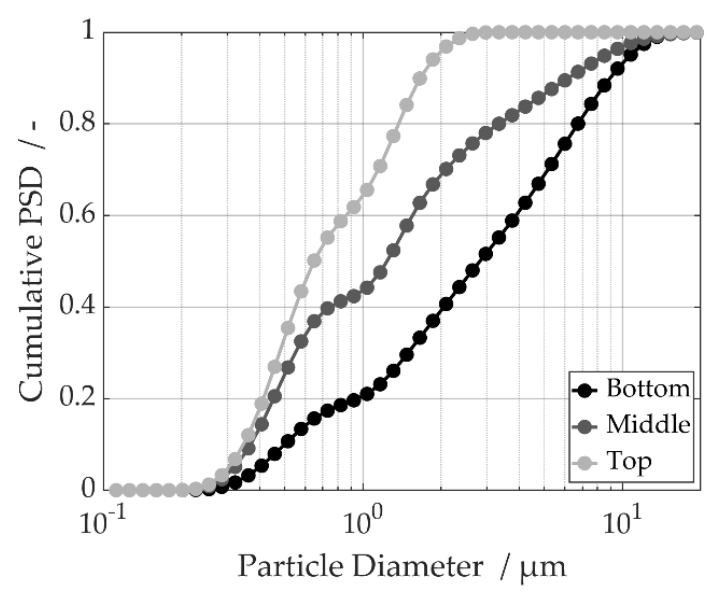

(d)

Figure 9. Sediment particle size distributions for the three cases and at bottom, middle and top axial position. Blue: 20,000 rpm; Red: 40,000 rpm; Black: Increasing rotational speed. (a) Characteristic particle sizes, squares: $x_{10}$; triangles: $x_{50}$ with dashed lines as guides to the eye; stars: $x_{90}$. (b-d) Detailed particle size distributions for the three cases at axial positions bottom (darkest), middle (moderate shade), top (lightest).

Considering the results for carbon content in Figure 10 provides further indications about the differing sediment constitution. In good agreement with expectations, the carbon content at the bottom is less than $3 \% \mathrm{C}$ in all cases, indicating that solely LFP particles are separated immediately after the inlet, regardless of the operational setting. All cases show an increasing carbon content along the rotor, too, according to expectations.

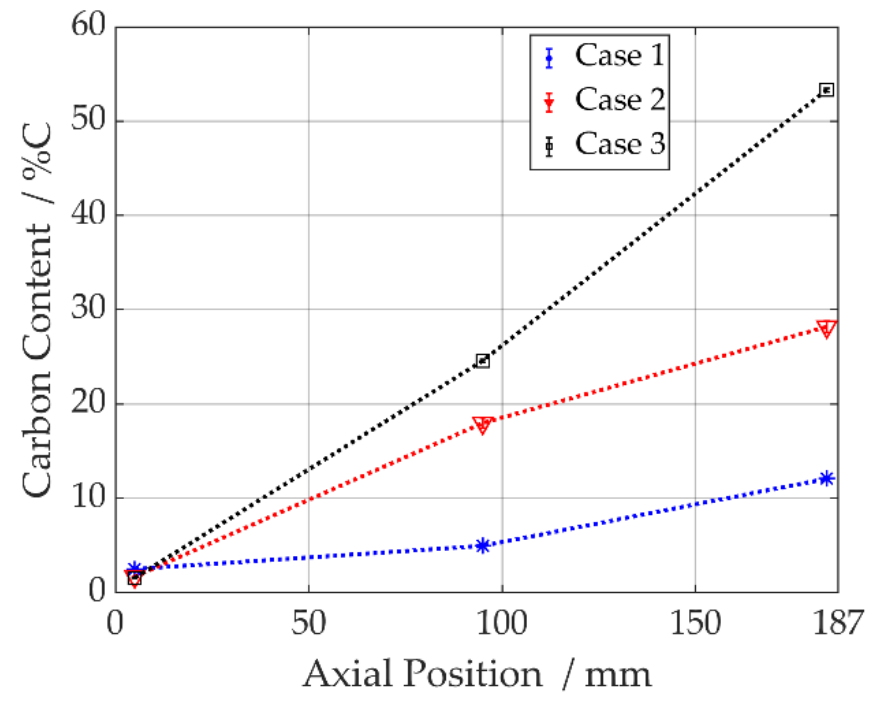

Figure 10. Sediment overall carbon content for the three cases at bottom, middle and top axial position. Blue: 20,000 rpm; Red: 40,000 rpm; Black: Increasing rotational speed. Squares: mean values; bars: Standard deviations; lines are guides to the eye.

The first case's overall low carbon contents (middle $5 \%$, top $12 \%$ C) suggest no or only low amounts of CB. According to the feed PSD (Figure 3) for this case, agglomerates do not play a crucial role. Separation conditions seem too weak to make numerous CB particles settle, as anticipated.

Equally according to assumptions, the carbon contents in case 2 is higher in the middle $(18 \% \mathrm{C})$ and at the top $(28 \% \mathrm{C})$ compared to case 1 . Obviously, relatively more $\mathrm{CB}$ is separated under stronger conditions, besides a higher absolute yield of LFP, as the centrate results indicate. 
As a quick conclusion from the centrate results, the carbon content in case 3 sediment samples should be lower than in case 2. Yet, the opposite is the case, the carbon contents are the highest with about $25 \% \mathrm{C}$ in the middle and 53\% C at the top. Due to the suggested higher CB content in centrate in case 3 (Figure 8 ) and not significantly different overall solids separation efficiencies (i.e., expected absolute sediment amount distributed in the rotor) between case 2 and 3 (Figure 6), these measurements are rather counterintuitive in the first instance. A possible explanation is given in Section 4.

\section{Discussion}

On the whole, the expectations based on the theoretical foundations are met to a great extent. Applying weak separation conditions, only the fastest settling particles are separated, that are mainly LFP and only few CB particles, if at all. This operational procedure results in a sediment containing practically only LFP (besides the carbon coating and binders). However, although a sediment very rich in LFP is desirable in terms of maximum LFP recovery for further recycling processing of the active material, the absolute yield of LFP is comparably low, regarding the dropping overall separation efficiency in Figure 6. This flaw may for example be tackled recirculating the centrate or setting up a centrifuge cascade, but these approaches would enhance the outlay in directions that are not intended at the actual state of this work. Under constantly strong separation conditions, a greater share of CB particles is separated alongside a larger absolute amount of LFP, compared to weaker separation conditions. So, the advantage of gaining an enhanced absolute active material yield is at the expense of a measurable contamination with CB. All things considered, both process modes with constant rotational speed resulted approximately in the anticipated temporal behavior: Overall separation efficiency decreases with ongoing time, centrate PSD contains coarser particles and centrate carbon contents offer logical supplements to these measurements, confirming the first assumptions.

With the intention to combine the best of both strategies, a rotational speed increase is examined as a new approach to counteract the temporal behavior. Centrate measurements suggest that almost constant separation conditions can be maintained with this procedure. The overall separation efficiency, centrate carbon content and especially centrate PSDs reveal approximately no variation over time. However, the overall separation efficiency is on a level too high to imply that only LFP is separated. Consequently, the rotational speed curve is expedient for keeping the centrate properties constant, but precisely the values set are presumably too high, and the accurate rotational speed curve lies possibly in a sense shifted versus the one applied. Reasons may lie in vortexes (back-)mixing the dispersion inside the rotor to some extent, which are not regarded in the centrifuge model for the time being, as well as other simplifications and imperfections of the model that served as basis to determine the rotational speed curve.

An increasing carbon content in sediment over the rotor length is also observed in all three cases and again meets expectations. On first examination, though, the comparably high carbon contents in middle and top sediment samples in the case with adapted rotational speed appear counterintuitive since these measurements contradict the intention to achieve complete fractionation of LFP and CB, which seems to be roughly fulfilled considering the centrate results. Of course, small vortexes and disturbances may complicate factual pure fractionation, but the strategy appears to work regarding the nearly constant and high carbon content in centrate. Against this background, the measured carbon contents are distinctly above expectations and not evident to explain. Nevertheless, it should firstly be stressed that all carbon content measurements only provide relative values and definite absolute conclusions cannot be drawn from the information provided by all given options for sample analysis. Secondly, endeavoring for an explanation, a closer look on the feed PSDs might be worthwhile.

As a result of the individual preparation of the feed dispersion for each of the three cases, they do not have identical PSDs, as formerly shown in Figure 3. As stated there, the feed dispersions in case 2 and 3 show a striking coarse fraction and strong tendency to agglomerate. It cannot be stated with certainty which amount of agglomerates entered the process and whether the agglomerates are stable or break during their residence time inside the rotor. 
Anyhow, agglomerates seem to have entered the centrifuge in case 2 and 3 . They might be more likely to break with stronger centrifugal forces acting on them, i.e., at high rotational speeds, like in case 2 or the end of case 3 . If they are broken, CB and LFP particles settle individually at their specific velocities. Conversely, if rotational speed is low, like in the first part of the curve in case 3 , agglomerates possibly do not break or take longer time to do so. Breaking after some time means that $\mathrm{CB}$ particles contained in an agglomerate are carried along a part of the way to the sediment until they are released to settle at their individual velocity. Both variants enhance the likelihood that $\mathrm{CB}$ particles reach sediment. Diluted for PSD measurements, resuspended sediment samples have a great tendency to agglomerate (again).

The essential difference between constantly high and increasing rotational speed is that in the former case, the likelihood for agglomerates to break is higher from the beginning and therefore, more individual particles settle separately during the entire process time. By contrast, applying an increasing rotational speed the forces are probably only strong enough to cause breach in the later course and for a certain duration unbroken agglomerates settle. According to theory, CB particles or comparably small individual particles are less likely to arrive at sediment than LFP particles or comparably great agglomerates, so probably a higher $\mathrm{CB}$ reaches sediment when agglomerates containing $\mathrm{CB}$ are not broken. This entire explanation is to be regarded as a hypothesis that requires further examination.

Apart from the controversial results for sediment carbon content, the reported results can be seen as a first proof that an appropriate increase of rotational speed can counteract the otherwise declining separation efficiency and keep centrate properties constant. This motivates to continue working on the approach to separate LFP and CB through a centrifugation step and recover LFP in the sediment as purely as possible. The latter point inevitably requires a verified explanation of the carbon contents measured and expedient adaptions in process design. It is intended to install an ultrasound flow-through cell before the centrifuge inlet to guarantee agglomerate-free feed. The precise rotational speed curve applied seems to lead approximately to the desired outcome. Still, small variances and the too high overall separation efficiency show that a more sensitive rotational speed setting would be preferable. The great benefit of the centrifuge model is therefore supposed to disclose when it is combined with on-line measurement techniques to realize a model-based control concept that the authors aim to present in future publications. According to this concept, rotational speed shall be adapted based on model predictions and precisely tuned corresponding to on-line measurements (PSD and centrate composition, like [37]). In this way, the authors aim to be able to recover an approximately pure LFP sediment that can eventually be re-used to manufacture new LIB cathodes. There is a good prospect that once the entire procedure is validated to work for LFP-based cathode material, centrifugation may also be applied to fractionate anode material (graphite), or generally black mass whose constituents are processible in water, which would contribute to a new, more environmentally sound recovery process chain.

\section{Conclusions}

Centrifugation was investigated as a technique for a physical separation step of black mass into its components as part of a direct recycling process chain for lithium-ion batteries. A tubular centrifuge is used to examine fractionation of an exemplary cathode material dispersion containing LFP and carbon black particles. Commonly operated at fixed settings, tubular centrifuges do not deliver constant output properties, but separation conditions that diminish over time, which would not serve the purpose to recover pure fractions of LFP and carbon black. According to theoretical foundations, LFP should be recovered as sediment, while carbon black stays in the centrate. Three operational strategies have therefore been examined concerning the temporal development of the centrate and sediment properties, two cases of constantly low $(20,000 \mathrm{rpm})$ and constantly high $(40,000 \mathrm{rpm})$ rotational speed, as well as a rotational speed increase based on a process model. The latter was desired to achieve constant centrate properties and a sediment rich in LFP. Expectations have been met 
concerning centrate. Overall solids content, particle size distributions and carbon content showed the anticipated temporal dependency when constant rotational speed was applied, whereas they remained mostly steady with increasing rotational speed. In that respect, rotational speed increase confirms to serve as suitable strategy to control the centrifuge output. However, sediment measurements reveal discrepancies from the expectations that may have arisen due to agglomerates in the feed dispersion. Once this issue is overcome, centrifugal fractionation may become a promising separation technique for lithium-ion battery active materials. In order to establish a usable set-up, the aim is to develop a model-based control concept for the operational settings of the centrifuge, which relies on on-line measurement tools for particle size distributions and composition of the dispersion as well.

Author Contributions: Conceptualization and funding acquisition, cooperation of all authors; formal analysis, software, validation, visualization, writing-original draft, T.S. (Tabea Sinn); data curation, investigation, methodology and project administration, T.S. (Tabea Sinn), A.F., T.S. (Thomas Stübinger) and A.W.; supervision, W.W., H.N. and M.G.; writing—review \& editing, A.F., T.S. (Thomas Stübinger), A.W., H.N. and M.G. Resources provided by the contributing institutions thanks to funding. All authors have read and agreed to the published version of the manuscript.

Funding: This research was funded by the German Federal Ministry of Education and Research (BMBF), grant number 033RK065A-D.

Acknowledgments: The authors would like to acknowledge and thank Carl Padberg Zentrifugenbau GmbH (CEPA, Lahr im Schwarzwald, Germany) for providing a free exemplary of tubular centrifuge model Z11 and service, which made the experiments in this paper possible. Furthermore, they acknowledge support by the KIT-Publication Fund of the Karlsruhe Institute of Technology.

Conflicts of Interest: The authors declare no conflict of interest. The funders had no role in the design of the study; in the collection, analyses, or interpretation of data; in the writing of the manuscript, or in the decision to publish the results.

\section{References}

1. Bauer, C.; Hofer, J.; Althaus, H.J.; Del Duce, A.; Simons, A. The environmental performance of current and future passenger vehicles: Life cycle assessment based on a novel scenario analysis framework. Appl. Energy 2015, 157, 871-883. [CrossRef]

2. Harper, G.; Sommerville, R.; Kendrick, E.; Driscoll, L.; Slater, P.; Stolkin, R.; Walton, A.; Christensen, P.; Heidrich, O.; Lambert, S.; et al. Recycling lithium-ion batteries from electric vehicles. Nature 2019, 575, 75-86. [CrossRef] [PubMed]

3. Gaines, L. The future of automotive lithium-ion battery recycling: Charting a sustainable course. Sustain. Mater. Technol. 2014, 1-2, 2-7. [CrossRef]

4. Lv, W.; Wang, Z.; Cao, H.; Sun, Y.; Zhang, Y.; Sun, Z. A Critical Review and Analysis on the Recycling of Spent Lithium-Ion Batteries. ACS Sustain. Chem. Eng. 2018, 6, 1504-1521. [CrossRef]

5. Ciez, R.E.; Whitacre, J.F. Examining different recycling processes for lithium-ion batteries. Nat. Sustain. 2019, 2, 148-156. [CrossRef]

6. Hanisch, C.; Loellhoeffel, T.; Diekmann, J.; Markley, K.J.; Haselrieder, W.; Kwade, A. Recycling of lithium-ion batteries: A novel method to separate coating and foil of electrodes. J. Clean. Prod. 2015, 108, 301-311. [CrossRef]

7. Sun, L.; Qiu, K. Vacuum pyrolysis and hydrometallurgical process for the recovery of valuable metals from spent lithium-ion batteries. J. Hazard. Mater. 2011, 194, 378-384. [CrossRef]

8. Tanong, K.; Coudert, L.; Mercier, G.; Blais, J.F. Recovery of metals from a mixture of various spent batteries by a hydrometallurgical process. J. Environ. Manag. 2016, 181, 95-107. [CrossRef]

9. Yang, Y.; Xu, S.; He, Y. Lithium recycling and cathode material regeneration from acid leach liquor of spent lithium-ion battery via facile co-extraction and co-precipitation processes. Waste Manag. 2017, 64, $219-227$. [CrossRef]

10. Zhan, R.; Oldenburg, Z.; Pan, L. Recovery of active cathode materials from lithium-ion batteries using froth flotation. Sustain. Mater. Technol. 2018, 17, 9. [CrossRef]

11. Li, X.; Zhang, J.; Song, D.; Song, J.; Zhang, L. Direct regeneration of recycled cathode material mixture from scrapped LiFePO4 batteries. J. Power Sources 2017, 345, 78-84. [CrossRef] 
12. Guerfi, A.; Kaneko, M.; Petitclerc, M.; Mori, M.; Zaghib, K. LiFePO4 water-soluble binder electrode for Li-ion batteries. J. Power Sources 2007, 163, 1047-1052. [CrossRef]

13. Anlauf, H. Recent Developments in Research and Machinery of Solid-Liquid Separation Processes. Dry Technol. 2006, 24, 1235-1241. [CrossRef]

14. Leung, W.W. Centrifugal Separations in Biotechnology; Elsevier Science: Amsterdam, The Netherlands, 2007.

15. Stokes, G.G. On the effect of the internal friction of fluids on the motion of pendulums. Transact. Camb. Philos. Soc. 1850, 9, 8-106.

16. Flegler, A.; Schneider, M.; Prieschl, J.; Stevens, R.; Vinnay, T.; Mandel, K. Continuous flow synthesis and cleaning of nano layered double hydroxides and the potential of the route to adjust round or platelet nanoparticle morphology. RSC Adv. 2016, 6, 57236-57244. [CrossRef]

17. Konrath, M.; Brenner, A.K.; Dillner, E.; Nirschl, H. Centrifugal classification of ultrafine particles: Influence of suspension properties and operating parameters on classification sharpness. Spt. Purif. Technol. 2015, 156, 61-70. [CrossRef]

18. Spelter, L.E.; Meyer, K.; Nirschl, H. Screening of Colloids by Semicontinuous Centrifugation. Chem. Eng. Technol. 2012, 35, 1486-1494. [CrossRef]

19. Konrath, M.; Hackbarth, M.; Nirschl, H. Process monitoring and control for constant separation conditions in centrifugal classification of fine particles. Adv. Powder Technol. 2014, 25, 991-998. [CrossRef]

20. Spelter, L.E.; Steiwand, A.; Nirschl, H. Processing of dispersions containing fine particles or biological products in tubular bowl centrifuges. Chem. Eng. Sci. 2010, 65, 4173-4181. [CrossRef]

21. Spelter, L.E.; Schirner, J.; Nirschl, H. A novel approach for determining the flow patterns in centrifuges by means of Laser-Doppler-Anemometry. Chem. Eng. Sci. 2011, 66, 4020-4028. [CrossRef]

22. Konrath, M.; Gorenflo, J.; Hübner, N.; Nirschl, H. Application of magnetic bearing technology in high-speed centrifugation. Chem. Eng. Sci. 2016, 147, 65-73. [CrossRef]

23. Gleiß, M. Dynamische Simulation der Mechanischen Flüssigkeitsabtrennung in Vollmantelzentrifugen; KIT Scientific Publishing: Karlsruhe, Germany, 2018. [CrossRef]

24. Gleiss, M.; Nirschl, H. Modeling Separation Processes in Decanter Centrifuges by Considering the Sediment Build-Up. Chem. Eng. Sci. 2015, 38, 1873-1882. [CrossRef]

25. Michaels, A.S.; Bolger, J.C. Settling rates and sediment volumes of flocculated kaolin suspensions. Ind. Eng. Chem. Funda. 1962, 1, 24-33. [CrossRef]

26. Sambuichi, M.; Nakakura, H.; Osasa, K. Zone settling of concentrated slurries in a centrifugal field. J. Chem. Eng. Jpn. 1991, 24, 489-494. [CrossRef]

27. Stickland, A.D. Compressional rheology: A tool for understanding compressibility effects in sludge dewatering. Water Res. 2015, 82, 37-46. [CrossRef]

28. Tiller, F.M.; Khatib, Z. The theory of sediment volumes of compressible, particulate structures. J. Colloid Interface Sci. 1984, 100, 55-67. [CrossRef]

29. Tsai, F.Y.; Jhang, J.H.; Hsieh, H.W.; Li, C.C. Dispersion, agglomeration, and gelation of LiFePO4 in water-based slurry. J. Power Sources 2016, 310, 47-53. [CrossRef]

30. Balbierer, R.; Gordon, R.; Schuhmann, S.; Willenbacher, N.; Nirschl, H.; Guthausen, G. Sedimentation of lithium-iron-phosphate and carbon black particles in opaque suspensions used for lithium-ion-battery electrodes. J. Mater. Sci. 2019, 54, 5682-5694. [CrossRef]

31. Richardson, J.; Zaki, W. The sedimentation of a suspension of uniform spheres under conditions of viscous flow. Chem. Eng. Sci. 1954, 3, 65-73. [CrossRef]

32. Bülow, F.; Nirschl, H.; Dörfler, W. On the settling behaviour of polydisperse particle clouds in viscous fluids. Eur. J. Mech. B Fluids 2015, 50, 19-26. [CrossRef]

33. Garrido, P.; Concha, F.; Bürger, R. Settling velocities of particulate systems: 14. Unified model of sedimentation, centrifugation and filtration of flocculated suspensions. Int. J. Miner. Process. 2003, 72, 57-74. [CrossRef]

34. Lerche, D. Dispersion Stability and Particle Characterization by Sedimentation Kinetics in a Centrifugal Field. J. Dispers. Sci. Technol. 2002, 23, 699-709. [CrossRef]

35. Spelter, L.E.; Nirschl, H. Classification of Fine Particles in High-Speed Centrifuges. Chem. Eng. Technol. 2010, 33, 1276-1282. [CrossRef]

36. Gleiß, M.; Sinn, T.; Nirschl, M. A dynamic model to predict separation behaviour and sediment build-up of colloidal silica particles within tubular centrifuges. Adv. Powder Technol. 2020, under review. 
37. Winkler, M.; Sonner, H.; Gleiss, M.; Nirschl, H. Fractionation of ultrafine particles: Evaluation of separation efficiency by UV/vis spectroscopy. Chem. Eng. Sci. 2020, 213, 115374. [CrossRef]

Publisher's Note: MDPI stays neutral with regard to jurisdictional claims in published maps and institutional affiliations.

(C) 2020 by the authors. Licensee MDPI, Basel, Switzerland. This article is an open access article distributed under the terms and conditions of the Creative Commons Attribution (CC BY) license (http://creativecommons.org/licenses/by/4.0/). 